\title{
Perspective of Adults With Neurofibromatosis 1 and Cutaneous Neurofibromas
}

\author{
Implications for Clinical Trials
}

\begin{abstract}
Ashley Cannon, PhD, MS, * Dominique C. Pichard, MD, * Pamela L. Wolters, PhD, Sarah Adsit, MPAS, Gregg Erickson, BA, Andrés J. Lessing, MBA, Peng Li, PhD, Whitney Narmore, BS, Claas Röhl, BA, Tena Rosser, MD, Brigitte C. Widemann, MD, Jaishri O. Blakeley, MD, and Scott R. Plotkin, MD, PhD, on behalf of the REiNS International Collaboration
\end{abstract}

Neurology ${ }^{\circledR}$ 2021;97:S15-S24. doi:10.1212/WNL.0000000000012425

\begin{abstract}
Objective

To assess the perspectives of adults with neurofibromatosis 1 (NF1) regarding cutaneous neurofibroma ( $\mathrm{cNF}$ ) morbidity, treatment options, and acceptable risk-benefit ratio to facilitate the design of patient-centered clinical trials.
\end{abstract}

\section{Methods}

An online survey developed by multidisciplinary experts and patient representatives of the Response Evaluation in Neurofibromatosis and Schwannomatosis (REiNS) cNF Working Group was distributed to adults with NF1 $(n=3,734)$ in the largest international database of individuals with any form of NF. Eligibility criteria included self-reported NF1 diagnosis, age $\geq 18$ years, $\geq 1 \mathrm{cNF}$, and ability to read English.

\section{Results}

A total of 548 adults with NF1 responded to the survey. Respondents ranked appearance, number, and then location as the most bothersome features of raised cNF. Seventy-five percent of respondents considered a partial decrease of $33 \%-66 \%$ in the number or size of cNF as a meaningful response to experimental treatments. Most respondents (48\%-58\%) were willing to try available cNF treatments but were not aware of options outside of surgical removal. Regarding experimental agents, respondents favored topical, then oral medications. Most individuals $(>65 \%)$ reported being "very much" or "extremely willing" to try experimental treatments, especially those with the highest cNF burden. Many respondents were not willing to tolerate side effects like nausea/vomiting (51\%) and rash (46\%). The greatest barriers to participation in cNF clinical trials were cost of participation and need to take time off work.

\section{Conclusions}

Most adults with NF1 are willing to consider experimental therapies for treatment of cNF. These data will guide the design of patient-centered clinical trials for adults with cNF.

\author{
Correspondence \\ Dr. Cannon \\ ashleycannon@uabmc.edu
}




\section{Glossary}

$\mathrm{CI}=$ confidence interval; $\mathrm{cNF}=$ cutaneous neurofibroma; NF1 = neurofibromatosis type $1 ; \mathbf{O R}=$ odds ratio; PRO = patientreported outcome; REiNS = Response Evaluation in Neurofibromatosis and Schwannomatosis.

Neurofibromatosis type 1 (NF1) is an autosomal dominant neurocutaneous disorder. A characteristic feature of NF1 is cutaneous neurofibroma (cNF), benign nerve sheath tumors involving the skin, which affect more than 99\% of adults with NF1. ${ }^{1}$ These tumors commonly appear in adolescence and continue to develop throughout adulthood. ${ }^{2}$ The cNF may be flat or raised, small (millimeters) or large (centimeters), skin-colored, pink, or violaceous. Tumor burden can vary widely as well as within different body areas of the same individual. ${ }^{3}$ Although these tumors do not have malignant potential, cNF have significant negative effects on quality of life. ${ }^{4-7}$ Physical symptoms may include pain and pruritus. ${ }^{8}$

Despite the high prevalence of cNF in adults with NF1 and the significant associated morbidity, treatment options are limited to surgical or destructive methods such as electrodessication, radiofrequency ablation, and laser. The disadvantages of these techniques are that they only target a subset of cNF, can result in scarring, may require general anesthesia, and are variably available. Thus, there is a strong unmet need to develop effective medical therapies for cNF.

With the exception of a small European study, ${ }^{9}$ there is little information concerning how patients assess cNF-related morbidity and how they view current and potential cNF treatments. Patient perspective is critical to optimize the development and implementation of therapies that maximize patient safety and satisfaction. Furthermore, trials will likely need to document meaningful clinical benefit in addition to biologic effect to obtain regulatory approval. The study aim was to survey adults with NF1 and cNF to understand their views regarding $\mathrm{cNF}$ and treatments to inform the design of patient-centered clinical trials.

\section{Methods}

\section{Standard Protocol Approvals, Registrations, and Patient Consents}

This study was approved by the University of Alabama at Birmingham's Institutional Review Board. Study participants acknowledged that they met study inclusion criteria and consented to participate by clicking on the survey link.

\section{Survey Development}

The patient survey was created by the Response Evaluation in Neurofibromatosis and Schwannomatosis (REiNS) Cutaneous Neurofibroma Working Group, which is composed of an international group of clinical researchers and patient representatives. ${ }^{10,11}$ The survey was designed to collect details about the patient's cNF (e.g., burden, location), views on morbidity related to specific aspects of cNF (e.g., body location, size, number, itch), and views regarding current and potential future $\mathrm{cNF}$ treatment (e.g., meaningful response, treatment modalities, side effects, and outcome measures). The survey was reviewed by a representative from a regulatory agency and validated by 6 experts in the field of cNFs. Next, we conducted a pilot test of the survey by patient representatives in REiNS to ensure questions were understandable, were relevant, and encompass the issues that may be present in this population. The complete survey can be found on the REiNS website on the Cutaneous Neurofibroma Working Group's page (ccrod.cancer.gov/confluence/display/REINS/Home).

Survey questions used 5-point Likert scales to measure ordered scale responses. In addition, 2 consecutive questions asked what minimum decrease in both number and size of cNF would be acceptable to patients after participating in a treatment trial. These questions were accompanied by baseline images of the face and posterior trunk of an individual with NF1 and cNF representing $0 \%$ shrinkage (i.e., no treatment effect). The images were digitally manipulated into a series visually representing a $33 \%, 66 \%$, and $100 \%$ decrease in the size of $\mathrm{CNF}$ (series 1; figure 1A) and the number of $\mathrm{cNF}$ (series 2; figure 1A). Two openended questions were included to assess qualitative responses.

The survey was built in REDCap (Research Electronic Data Capture), a secure web-based application designed to support data capture for research studies. ${ }^{12}$

\section{Study Population}

The REDCap survey link was distributed via the Children's Tumor Foundation NF Registry, ${ }^{13}$ a web-based patiententered database. During the active survey period, the NF Registry comprised 3,734 adults with NF1, of whom 2,421 $(64.8 \%)$ were female, and the average age was 39.4 years. The survey link was distributed by email in July 2018 and was active for 1 month. A reminder email was sent 3 weeks after the initial survey email. Inclusion criteria for the study were adults ( $\geq 18$ year old) with NF1, at least $1 \mathrm{cNF}$, and ability to read English.

\section{Statistical Analysis}

Data were summarized using descriptive statistics: mean and SD for continuous variables and frequency count and proportion for categorical variables. Chi-square tests were used to evaluate the association between 2 categorical variables of interest, including sex (male/female), age ( $18-49$ years/ $\geq 50$ 


\section{A}

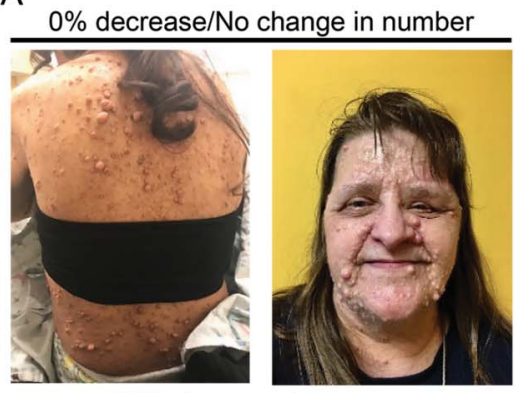

$66 \%$ decrease in number
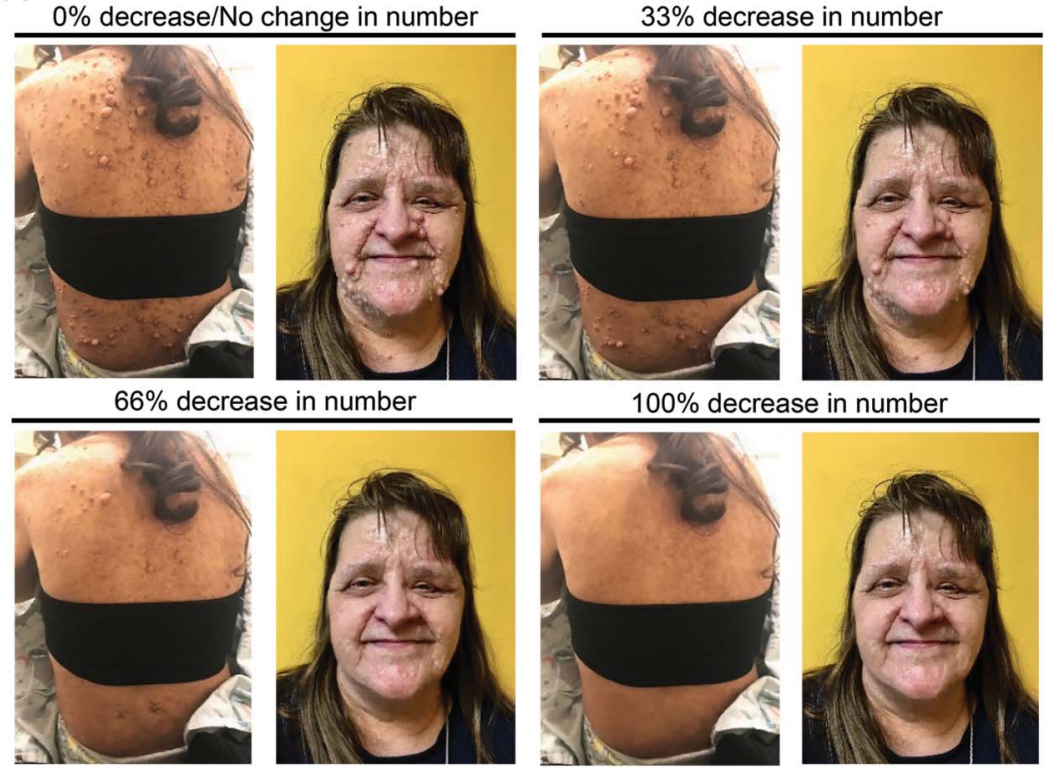

$100 \%$ decrease in number
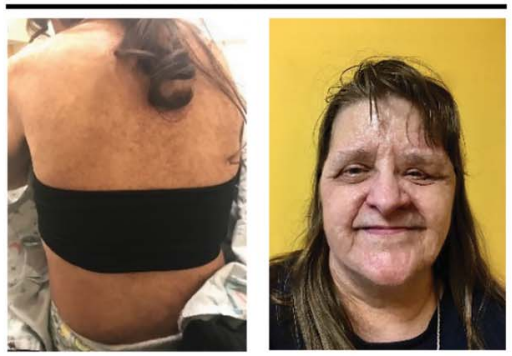

B

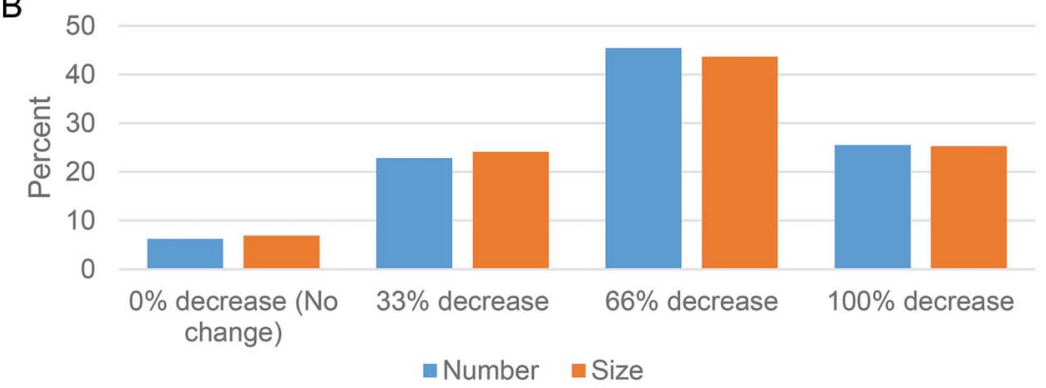

C

I would prefer a scar instead of a cutaneous neurofibroma

I would prefer skin color changes (lighter or darker) instead of a cutaneous..

If my raised cutaneous neurofibromas looked more flat I would be okay with my...

If the pain went away I would be okay with the way my cutaneous neurofibromas...

If the itching went away I would be okay with the way my cutaneous...

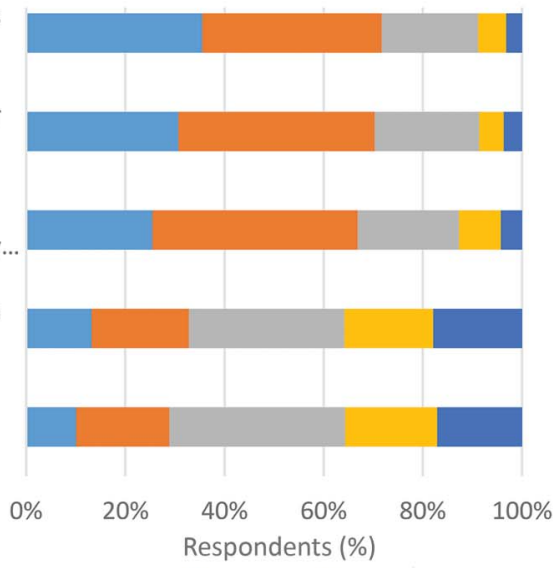

- Strongly Agree $\square$ Agree $\square$ Neither Agree nor Disagree $\square$ Disagree $\square$ Strongly Disagree
(A-B) Survey respondents were asked: "When thinking about the raised cutaneous neurofibromas that bother you the most, what is the minimum decrease in [number/size] that would be acceptable to you after participating in a treatment trial?" The questions were accompanied by baseline images and digitally manipulated into a series visually representing a 33\%,66\%, and $100 \%$ decrease in CNF number and size. (A) Images used for cNF number decrease. (B) Graphical representation of the responses. (C) A 5-point Likert scale was utilized to assess agreement with the statements listed on the y axis. years), family history of NF1 (familial/proband), and cNF burden (1-99 cNF/ $\geq 100 \mathrm{cNF}$ ). Odds ratio (OR) and the 95\% confidence interval (CI) were provided for the strength of significant association. Spearman correlation coefficients were used to evaluate the relationship between raised and flat $\mathrm{cNF}$ as well as number and size of cNF. To systematically classify text data for coding and theme identification, conventional content analysis using inductive techniques was performed by 2 investigators (A.C., W.N.). ${ }^{14}$ All statistical analyses were conducted using SAS 9.4.

\section{Data Availability}

With the permission of the corresponding author and the institutions, all data used for analysis will be shared after ethics approval if requested by other investigators for reasonable purposes of replicating procedures and results. 
Table 1 Survey Respondent Characteristics

\begin{tabular}{|c|c|}
\hline Characteristics $(n=548)$ & Mean \pm SD or $n(\%)$ \\
\hline Age, y & $44.9 \pm 13.7$ \\
\hline \multicolumn{2}{|l|}{ Sex } \\
\hline Female & $385(67.7)$ \\
\hline Male & $171(30.1)$ \\
\hline Other & $1(0.2)$ \\
\hline Not answered & $12(2.1)$ \\
\hline \multicolumn{2}{|l|}{ Race } \\
\hline American Indian or Alaska Native & $7(1.2)$ \\
\hline Asian & $20(3.5)$ \\
\hline Black or African American & $15(2.6)$ \\
\hline $\begin{array}{l}\text { Native Hawaiian or other Pacific } \\
\text { Islander }\end{array}$ & $5(0.9)$ \\
\hline White & $488(85.8)$ \\
\hline Other & $20(3.5)$ \\
\hline Not answered & $14(2.5)$ \\
\hline
\end{tabular}

Ethnicity

\begin{tabular}{ll}
\hline Hispanic or Latino & $36(6.3)$ \\
\hline Not Hispanic or Latino & $413(72.6)$ \\
\hline Other & $91(16.0)$ \\
\hline Not answered & $29(5.1)$ \\
\hline Country & $442(81.0)$ \\
\hline United States & $36(6.6)$ \\
\hline Canada & $19(3.5)$ \\
\hline United Kingdom & $15(2.7)$ \\
\hline Australia & $34(6.2)$ \\
\hline Other
\end{tabular}

\section{Education}

\begin{tabular}{ll}
\hline Did not complete high school & $21(3.7)$ \\
\hline High school degree or equivalent & $95(16.7)$ \\
\hline Some college but no degree & $131(23.0)$ \\
\hline Associate degree & $83(14.6)$ \\
\hline Bachelor degree & $145(25.5)$ \\
\hline Graduate degree & $80(14.1)$ \\
\hline Not answered & $14(2.5)$ \\
\hline Work outside of home & $343(60.3)$ \\
\hline Yes & $213(37.4)$ \\
\hline No & $13(2.3)$ \\
\hline Not answered &
\end{tabular}

Table 1 Survey Respondent Characteristics (continued)

\begin{tabular}{ll}
\hline \multicolumn{2}{l}{ First person in family with neurofibromatosis } \\
\hline Yes & $368(64.7)$ \\
\hline No & $188(33.0)$ \\
\hline Not answered & $13(2.3)$ \\
\hline
\end{tabular}

${ }^{a}$ No more than 4 responses for any country listed in other.

\section{Results}

\section{Survey Respondent Characteristics}

Emails with survey links were sent to 3,734 NF Registry participants using the listed email addresses; 1,639 (43.8\%) opened the NF Registry emails. Of the 1,639 who opened the emails, 603 (36.8\%) individuals accessed the survey links and 548 (33.4\%) individuals completed the survey. The overall response rate for those opened NF Registry emails was 33.4\% $(548 / 1,639)$. For those who accessed the survey, the response rate was $90.9 \%(548 / 603)$. The respondents represented about $14.7 \%(548 / 3,734)$ of the total NF Registry participants. Most respondents were female (67.7\%), were White (85.8\%), had a minimum of some college education $(77.2 \%)$, worked outside the home $(60.3 \%)$, were the first in the family diagnosed with NF1 (64.7\%), and had mean age of 44.9 years. Survey respondent characteristics were similar to that of the NF Registry participants ${ }^{13}$ (table 1 ).

\section{Location of cNF}

Features of cNF reported by study respondents are shown in table 2. Burden of raised cNF ranged from low (1-19 cNF, $15.6 \%$ ) to high ( $>500 \mathrm{cNF}, 21.1 \%)$ with most in the moderate range (20-500 cNF, 56.4\%). Most respondents (55.9\%) also reported having flat cNF. cNF were described in essentially all body locations, with highest percentage reported for the trunk (86.8\%) followed by arms (79.3\%) and face (65.9\%).

\section{Bothersome cNF Features}

Participants ranked appearance, number, and then location as the most bothersome features of raised cNF. Nearly $60 \%$ of individuals reported being "very much" or "extremely" bothered by these features (figure $2 \mathrm{~A}$ ). Color of $\mathrm{cNF}$, on the other hand, was not bothersome to participants.

The trunk, face, and arms were ranked as the most bothersome body locations with cNF; more than $50 \%$ of individuals reported being "very much" or "extremely" bothered by cNF in these locations (figure 2B). Female respondents were more likely to be bothered by cNF number (OR 1.96 [CI 1.34, $2.92] ; p=0.0006)$ and appearance (OR 1.99 [CI 1.32, 2.98]; $p$ $=0.0008)$ than male respondents. The percentage of individuals who were "very much" or "extremely" bothered by cNF were similar between age groups, even though cNF burden increases with age. Responses were similar between 
Table 2 Study Respondent Cutaneous Neurofibroma (cNF) Features

\begin{tabular}{lc}
\hline cNF features & $\mathbf{N}(\%)$ \\
\hline Number of cNF over entire body & \\
\hline Not answered & $39(6.9)$ \\
\hline $\mathbf{1 - 1 9}$ & $89(15.6)$ \\
\hline $\mathbf{2 0 - 9 9}$ & $136(23.9)$ \\
\hline $\mathbf{1 0 0 - 5 0 0}$ & $185(32.5)$ \\
\hline$>\mathbf{5 0 0}$ & $122(21.1)$
\end{tabular}

Age at onset, y

\begin{tabular}{|c|c|}
\hline Not answered & $41(7.2)$ \\
\hline Younger than 10 & $147(25.8)$ \\
\hline $10-19$ & $239(42.0)$ \\
\hline $20-29$ & $104(18.3)$ \\
\hline $30-39$ & $30(5.3)$ \\
\hline 40 or older & $8(1.4)$ \\
\hline \multicolumn{2}{|l|}{ cNF Locations } \\
\hline Trunk & $494(86.8)$ \\
\hline Arms & 451 (79.3) \\
\hline Face & 375 (65.9) \\
\hline Neck & $364(64.0)$ \\
\hline Legs & $364(64.0)$ \\
\hline Hands & 334 (58.7) \\
\hline Feet & 301 (52.9) \\
\hline Nipple/areola & $300(52.7)$ \\
\hline Scalp & $289(50.8)$ \\
\hline Genitals & $222(39.0)$ \\
\hline Other & $39(6.9)$ \\
\hline \multicolumn{2}{|l|}{ Flat cNF } \\
\hline Yes & 318 (55.9) \\
\hline No & $86(15.1)$ \\
\hline I don't know & 130 (22.9) \\
\hline Not answered & $35(6.2)$ \\
\hline
\end{tabular}

individuals with a family history of NF1 and individuals who were the first person in the family diagnosed with NF1.

\section{Qualitative Effect of cNF}

Study participants were asked to provide an optional free text response to the question: "How do cutaneous neurofibromas affect you?" Conventional content analysis of the 244 responses (44.5\% of all survey respondents) showed that cNF affected psychological health (e.g., self-esteem, depression) in $73.8 \%$, physical health (e.g., pain, itching) in 49.6\%, and social wellbeing (e.g., intimacy, social isolation) in $33.2 \%$ of respondents (table 3 ). The following quote from a respondent demonstrates how cNF can profoundly affect adults living with NF1: "While pain is always present I don't have to talk about that, but people always see the tumors. I can hide my pain, I can't hide the quantity of tumors."

\section{Meaningful cNF Treatment Response}

Participants were shown images representing a discrete proportion of a decrease in size and a decrease in number of $\mathrm{cNF}$, and they were asked what the minimum acceptable change in response to a therapy would be for them. Based on the images presented, the most common minimum acceptable decrease was a $66 \%$ decrease in both cNF size and number (figure 1B). Importantly, only a quarter of respondents considered $100 \%$ clearance to be the minimum acceptable change. Patients' expectations regarding the minimum acceptable decrease in cNF size and number are highly correlated $(n=415 ; r=0.79, p<0.001)$. Individuals with a higher burden of cNF $(\geq 100)$ were more likely to choose a higher acceptable minimum decrease $(\geq 66 \%)$ in cNF number (OR 1.54 [CI 1.00, 2.37]; $p=0.0468)$ and size (OR 1.53 [CI 1.00, 2.32]; $p=$ $0.0475)$ than individuals with a lower burden of cNF $(\leq 100)$. Respondents also were asked to choose how long they would be willing to undergo treatment for $\mathrm{cNF}$ (multiple frequency selections were allowed). Responses were evenly distributed; however, the option with the highest response $(n=187,33 \%)$ was "Every day for the rest of your life."

\section{Preferences Regarding cNF Treatment Options}

Respondents were asked whether they had heard of, tried, or were willing to try the following currently available treatments: surgical removal, laser removal, radiofrequency ablation, and electrodessication (table 4). Many respondents were familiar with and underwent surgical removal of cNF. Although most individuals had never heard of the other treatments, they were willing to try these treatments ( $48 \%-58 \%)$. Statistical analysis showed that older individuals ( $>50$ years) were more likely to have undergone surgical removal of cNF (OR 2.87 [CI 1.82, $4.51] ; p=0.0001)$ than younger individuals (18-49 years). In general, individuals with a higher burden of $\mathrm{cNF}(\geq 100)$ were more likely to have undergone cNF treatments (OR 3.14 [CI 2.03, 4.86]; $p<0.0001)$. Although most individuals (88\%) showed willingness to try current cNF treatments, individuals with a higher burden of $\mathrm{cNF}(\geq 100)$ tended to be more willing to try these treatments than individuals with a lower burden of cNF $(\leq 100)$ (OR 1.72 [CI 0.95, 3.09]; $p=0.0690)$.

Respondents also were asked how much they agreed with several cNF treatment response statements (figure 1C). More than 65\% "agree" or "strongly agree" with the following statements: "I would prefer a scar instead of a cutaneous neurofibroma," "I would prefer skin color changes (lighter or darker) instead of a cutaneous neurofibroma," "If my raised cutaneous neurofibromas looked more flat I would be okay with my cutaneous neurofibromas."

Topical creams/ointment followed by oral medications were rated the most preferred experimental $\mathrm{cNF}$ treatment 
Figure 2 Views Related to Specific Aspects of Cutaneous Neurofibromas (cNF).

A

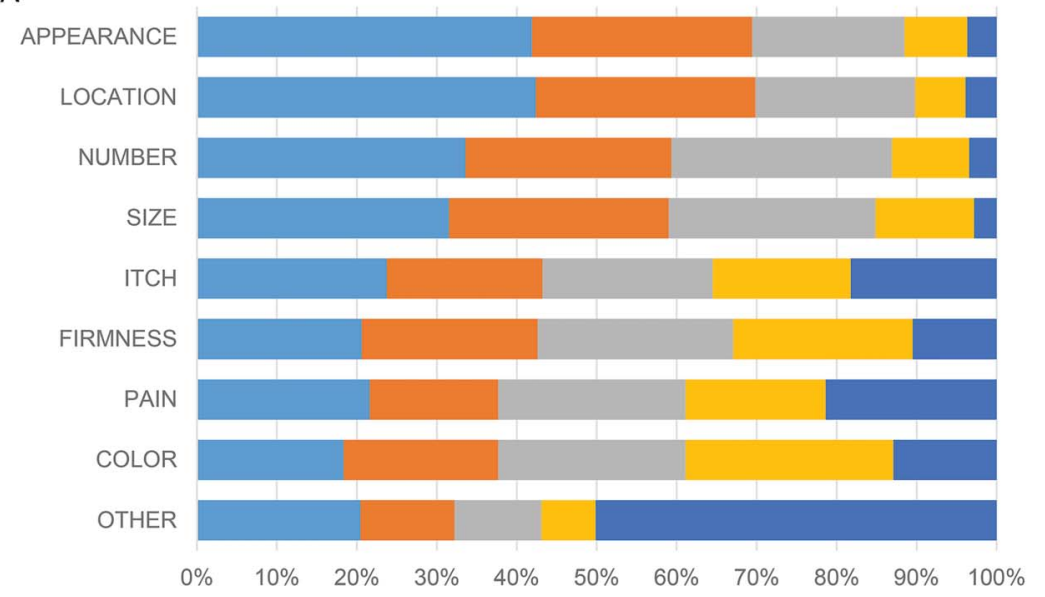

B

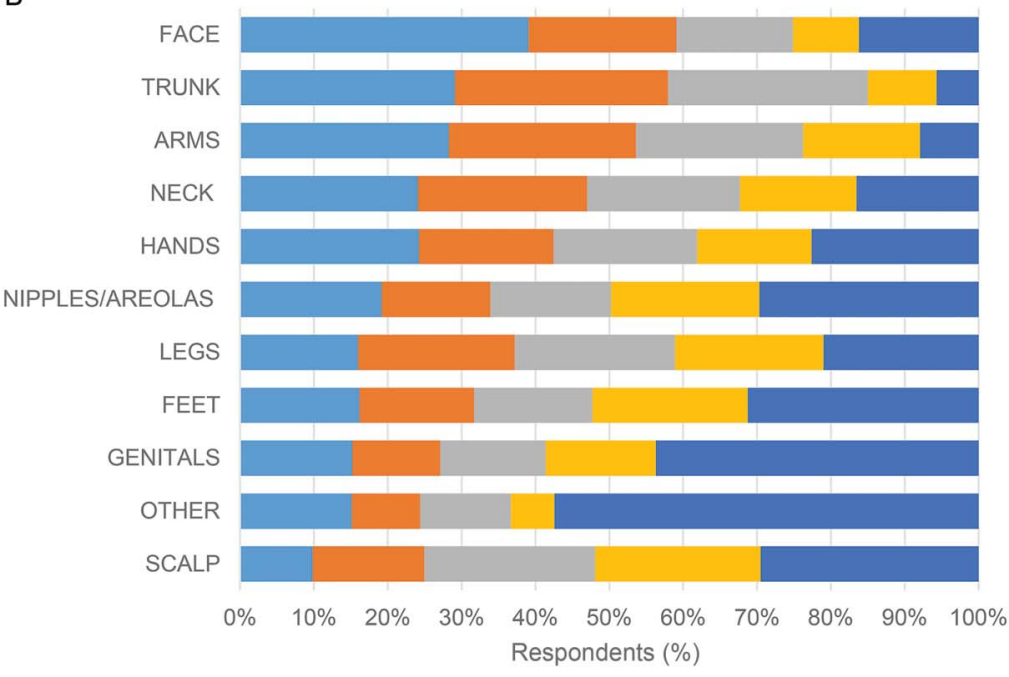

Extremely (5) $\quad$ Very much (4) $\quad$ Somewhat (3) $=$ Not so much (2) $\quad$ Not at all N/A (1) 5-point Likert scales were utilized for responses to the questions: (A) "How much does each FEATURE of your raised cNFs bother you (physically, cosmetically, or emotionally)?"; (B) "How much do your cNFs bother you on each AREA of your body (physically, cosmetically, or emotionally)?" formulations; more than $65 \%$ of individuals reporting being "very much" or "extremely willing" to try these treatment modalities (figure 3A). Furthermore, approximately $50 \%$ of respondents would be willing to try infusions and intralesional injections.

\section{Unacceptable cNF Treatment Side Effects}

Questions assessed the willingness to tolerate side effects known to be associated with current and experimental cNF treatments (figure $3 \mathrm{~B}$ ). Of the potential side effects, a minority of patients were "very much" or "extremely" willing to risk side effects like scarring (32\%) and skin color change (29\%). Conversely, about half of patients were "not so much" or "not at all" willing to risk side effects like nausea/vomiting (51\%) and rash (46\%).

\section{Barriers to Clinical Trial Participation}

The final survey question was an optional free text question asking "What might prevent you from participating in a clinical trial to treat your cutaneous neurofibromas?"
Conventional content analysis of the 175 responses (31.9\% of survey responders) showed that the barriers to cNF clinical trials include cost (financial, time, travel; 77\%), trial-specific concerns (side effects, eligibility; 26\%), lack of trial awareness (7\%), and current life situation (poor health, pregnancy; 6\%) (table 3 ). No barriers were reported by $21 \%$ of respondents.

\section{Discussion}

The mission of the REiNS Cutaneous Neurofibroma Working Group is to develop recommendations for clinical trial design, end points, and measurement tools for therapeutic trials targeting $\mathrm{cNF}$ in NF1. We strive to design clinical trials that are optimized based on the biology, current clinical care options, and patient perspective. This is the largest report of Englishlanguage patient-generated health data regarding $\mathrm{cNF}$.

Through this survey, we collected information about features of $\mathrm{cNF}$ that bother patients with NF1. The most bothersome 
Table 3 Conventional Content Analysis of Open-Ended Survey Questions

\begin{tabular}{|c|c|c|c|}
\hline Survey question & Major themes & Representative quotes & N (\%) \\
\hline \multirow[t]{3}{*}{$\begin{array}{l}\text { How do cutaneous neurofibromas } \\
\text { affect you? }\end{array}$} & $\begin{array}{l}\text { Psychological health } \\
\text { Psychological (anxiety, depression, } \\
\text { suicide) } \\
\text { Appearance } \\
\text { Self-esteem } \\
\text { Feel the need to conceal oneself } \\
\text { (clothes, makeup) } \\
\text { Loss of "normal" life } \\
\text { Embarrassment }\end{array}$ & $\begin{array}{l}\text { "I am able to still carry on my day to day activities. I hate } \\
\text { looking at myself in a mirror, am extremely self-conscious } \\
\text { about my appearance and what others think of me...even } \\
\text { my husband." }\end{array}$ & $180(73.8)$ \\
\hline & $\begin{array}{l}\text { Physical health } \\
\text { Physical (pain, itch, bleeding) } \\
\text { Progressive nature of NF1 } \\
\text { cNF location } \\
\text { Cancer concerns }\end{array}$ & $\begin{array}{l}\text { "Although most of mine are quite small, they are in } \\
\text { awkward places that rub, cause bleeding and extreme } \\
\text { itching." }\end{array}$ & $121(49.6)$ \\
\hline & $\begin{array}{l}\text { Social wellbeing } \\
\text { Hurtful comments/stares } \\
\text { Social isolation } \\
\text { Family planning/inheritance } \\
\text { considerations } \\
\text { Intimacy issues }\end{array}$ & $\begin{array}{l}\text { "It's been difficult to have and explore intimate } \\
\text { relationships with men because of my body's appearance. } \\
\text { I have been rejected because of the way my body looks." }\end{array}$ & $81(33.2)$ \\
\hline \multirow[t]{4}{*}{$\begin{array}{l}\text { What might prevent you from } \\
\text { participating in a clinical trial to treat } \\
\text { your cutaneous neurofibromas? }\end{array}$} & $\begin{array}{l}\text { Cost } \\
\text { Financial } \\
\text { Travel } \\
\text { Time commitment } \\
\text { Insurance concerns }\end{array}$ & $\begin{array}{l}\text { "Money is a huge concern! Not only money spent on any } \\
\text { procedures, but time away from work." }\end{array}$ & $135(77.1)$ \\
\hline & $\begin{array}{l}\text { Trial-specific concerns } \\
\text { Side effects } \\
\text { Comorbidities } \\
\text { Eligibility concerns } \\
\text { Previous negative experience } \\
\text { No proven efficacy } \\
\text { Distrust }\end{array}$ & "Fear of unknown side effects" & $46(26.3)$ \\
\hline & Lack of trial awareness & $\begin{array}{l}\text { "Don't know if any MDs in my area are willing to work with } \\
\text { an NF study." }\end{array}$ & $12(6.7)$ \\
\hline & $\begin{array}{l}\text { Current life situation } \\
\text { Lack of support } \\
\text { Poor health } \\
\text { Pregnancy/family planning/young } \\
\text { children }\end{array}$ & $\begin{array}{l}\text { "I'm trying to get pregnant so I don't want to ingest any } \\
\text { medication." }\end{array}$ & $11(6.3)$ \\
\hline
\end{tabular}

Abbreviations: $\mathrm{CNF}=$ cutaneous neurofibroma; $\mathrm{NF}=$ neurofibromatosis.

feature noted was appearance, which is a complex construct that includes multiple dimensions such as size, number, location, and color of tumors. Importantly, negative appearance refers to some physical feature that is undesirable, rather than a medical comorbidity. Related to appearance, the patients' qualitative responses indicated that their psychological and social well-being are negatively affected by $\mathrm{cNF}$, similar to what was found in the European study. ${ }^{9}$ This finding highlights the importance of using a patient-reported outcome (PRO) measure that will capture the effect of cNF appearance on quality of life and be sensitive to assessing clinical benefit in therapeutic trials. The responses also emphasize the need for developing psychosocial intervention trials to help patients cope with the effects of cNF.

Patients reported the location, number, and size of cNF as significantly bothersome features. Translating to clinical trial readiness, we cannot change the location of $\mathrm{cNF}$, but we can therapeutically target locations that were identified as most bothersome (trunk, face, arms) to be target sites for treatment, as they would likely have the greatest effect on quality of life. At present, there is no medical therapy to treat or prevent cNF. In the future, trials designed to prevent cNF formation are highly desirable as that would address patient concern regarding the number of cNF that develop. Based on patient input on desirable outcome, our current findings support using change in tumor size as a relevant primary endpoint and PRO measures as a secondary endpoint for cNF clinical trials as new agents enter the clinical testing stage.

Recently, selumetinib, a MEK inhibitor, was granted US Food and Drug Administration approval for treatment of inoperable plexiform neurofibromas based on clinical trials that demonstrated significant decrease in size of plexiform neurofibromas as well associated clinical benefit. ${ }^{15,16}$ Based on a decrease in size of plexiform neurofibromas, it is reasonable to 
Table 4 Awareness and Willingness to Try Currently Available Cutaneous Neurofibroma (cNF) Treatments

\begin{tabular}{|c|c|c|c|c|}
\hline Current cNF treatments & Surgical removal & Laser removal & Radiofrequency ablation & Electrodessication \\
\hline \multicolumn{5}{|l|}{ Heard of treatment } \\
\hline Yes & $353(62.0)$ & $217(38.1)$ & $72(12.6)$ & $191(33.6)$ \\
\hline No & $55(9.7)$ & $177(31.1)$ & $320(56.2)$ & $212(37.3)$ \\
\hline I don't know & $13(2.3)$ & $22(3.9)$ & $22(3.9)$ & $11(1.9)$ \\
\hline Not answered & $148(26.0)$ & $153(26.9)$ & $155(27.2)$ & $155(27.2)$ \\
\hline \multicolumn{5}{|l|}{ Tried treatment } \\
\hline Yes & $271(47.6)$ & $38(6.7)$ & $12(2.1)$ & $45(7.9)$ \\
\hline No & $147(25.8)$ & 375 (65.9) & $402(70.6)$ & $366(64.3)$ \\
\hline Not answered & $151(26.5)$ & $156(27.4)$ & $155(27.2)$ & $158(27.8)$ \\
\hline \multicolumn{5}{|l|}{ Willing to try treatment } \\
\hline Yes & $333(58.5)$ & $320(56.2)$ & $275(48.3)$ & $283(49.7)$ \\
\hline No & $17(3.0)$ & $10(1.8)$ & $13(2.3)$ & $22(3.9)$ \\
\hline Maybe & $67(11.8)$ & $86(15.1)$ & $128(22.5)$ & $107(18.8)$ \\
\hline Not answered & $152(26.7)$ & $153(27.0)$ & $153(26.9)$ & 157 (27.6) \\
\hline
\end{tabular}

Values are $\mathrm{n}(\%)$.

expect that MEK inhibitors or other medical therapies could decrease the size of cNF.

We asked participants to estimate the minimum decrease in size of cNF that would be acceptable after participating in a treatment trial. Only $25 \%$ of participants believed that complete clearance was necessary to consider a treatment "acceptable." Approximately $25 \%$ believed that either $0 \%$ or $25 \%$ shrinkage would be acceptable, and approximately $45 \%$ believed that $66 \%$ shrinkage would be acceptable. This acceptable partial response is consistent with a European study where $30 \%$ cNF clearance was considered effective by adults with NF1. ${ }^{9}$

Respondents also indicated they would prefer a scar or a flattened cNF to an elevated cNF. Given that most patients would be satisfied with some residual tumor or a scar, cNF shrinkage without complete resolution is a relevant clinical trial end point for use in future studies.

These survey data help identify potential clinical trial candidates and optimal treatment properties. Similar to findings in the European study, ${ }^{9}$ participants who had a higher burden of cNF (>100) were more likely to have tried existing therapeutic modalities (surgical removal or destructive methods), were more willing to try the existing therapies, and more than $65 \%$ were willing to consider therapeutic clinical trials. Participants were most interested in a topical therapy or oral therapy, but patients with high cNF burden were also willing to consider more invasive treatments such as infusions or intralesional agents. Study participants also expressed tolerance of potential dermatologic side effects such as scarring and skin color change (hyperpigmentation or hypopigmentation), but the majority were not willing to tolerate systemic side effects (nausea, vomiting, pain, fatigue, rash) or to take time off work. The European study reported similar results to our study. ${ }^{9}$ This finding indicates that clinical investigators should carefully evaluate the side effect profile of drugs being considered for clinical trials for cNF.

Finally, we assessed barriers to participation in clinical trials. Many participants answered that there were no barriers to participation and they were willing to try anything, but others identified possible barriers such as time required for participation in a clinical trial, travel required for visits, cost of participation, and fear of side effects. Based on the responses, future clinical trials should plan to minimize these factors. Decentralized trials to minimize the in-person evaluations required should be evaluated. Cost of participation, which includes cost of study requirements as well as cost of lost work, should also be considered. This could be minimized by reducing the number of in-person visits or scheduling required visits during off hours (i.e., nights, weekends), when feasible. Funding can be sought by investigators to cover the costs of required study laboratory studies and tests as well as travel expenses.

The survey was only offered in the English language, so we were only able to assess the effect of cNF on the English-speaking population. The survey participants were representative of the 
Figure 3 Willingness To Try Experimental Treatments and Risk Side Effects.

A

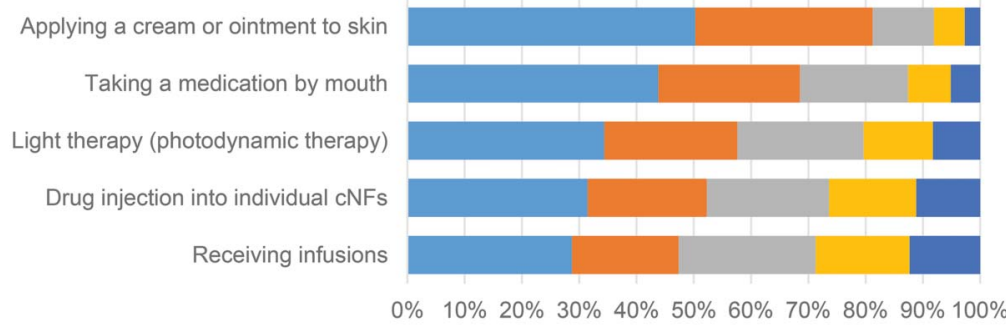

B

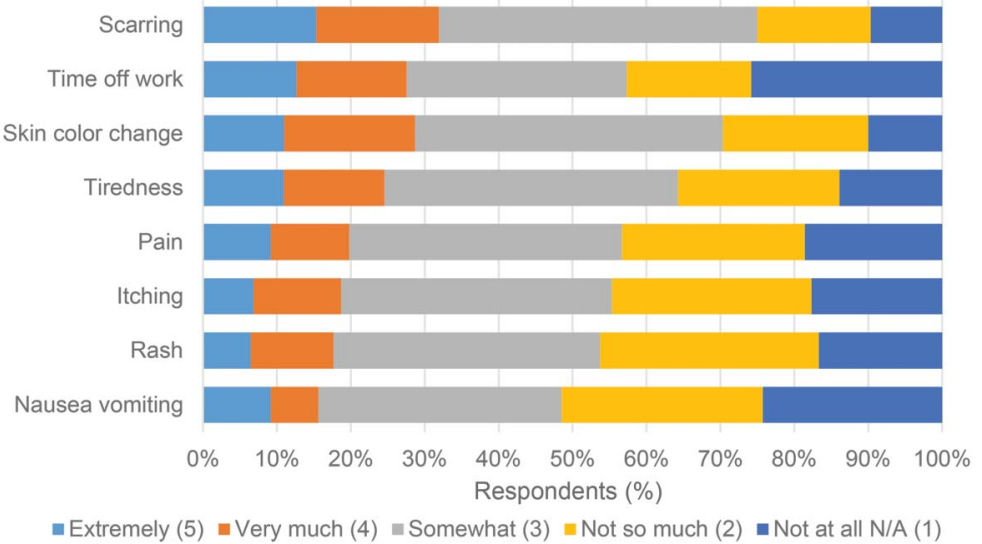

5-point Likert scale responses were utilized for the following questions: (A) "Assuming equal effectiveness and safety, what is your willingness to try these EXPERIMENTAL treatments for cutaneous neurofibromas?"; (B) "What side effects are you willing to risk for treatment of your cutaneous neurofibromas even if they may grow back later?"

NF registry demographics, which is heavily weighted to the United States, but not necessarily the general NF1 patient population. Future studies are needed to engage non-English speaking, non-White, and Hispanic individuals with NF1 to assess views regarding $\mathrm{cNF}$ and treatment.

This study explores the patient perspectives of 548 adults with NF1 and cNF about cNF morbidity and treatment, which is vital for the design and implementation of patient-centered treatment of cNF. Based on their responses, balancing desired outcomes with side effects, we propose topical or oral formulation of medication to target cNF. Identification of, or development of, a PRO measure that captures the burden of disease and psychosocial concerns, which will be sensitive to changes in cNF, is critical. End points for a clinical trial should include PRO measures to assess clinical benefit as well as a measurement of cNF size to test the efficacy of a treatment in decreasing size of $\mathrm{cNF}$, even if a trial does not achieve a $100 \%$ decrease of target $\mathrm{cNF}$. Flattening of $\mathrm{cNF}$ could be the desired end point based on responses in this survey. Future work includes understanding the perspective of adolescents and caregivers with regards to cNF prevention and treatment, identification of a cNF PRO, and development of an outcome measurement tool for size.

\section{Acknowledgment}

The authors thank the Children's Tumor Foundation for distributing the survey on behalf of the REiNS International Collaboration; Melissa Reyes, MD, Medical Officer at the
FDA, for survey development guidance; and contributions made by the REiNS Cutaneous Neurofibroma Working Group members (participated in working group meetings): Anat Stemmer-Rachamimov, Massachusetts General Hospital; Andrea Baldwin, National Cancer Institute; Christopher Moertel, University of Minnesota; Dawn Siegel, Medical College of Wisconsin; Deeann Wallis, University of Alabama at Birmingham; Kaleb Yohay, New York University; Kavita Sarin, Stanford University (coordinating role for working group meetings); Khaled Ezzedine, Assistance PubliqueHôpitaux de Paris; Krista Fredrick, REiNS Patient Representative; Maciej Mrugala, Mayo Clinic; Michael Fisher, Children's Hospital of Philadelphia; Pierre Wolkenstein, Hôpital Henri-Mondor; Robert Kesterson, University of Alabama at Birmingham; Shannon Langmead, Johns Hopkins University; Sharad Verma, Johns Hopkins University; Sheilagh Maguiness, University of Minnesota; Vanessa Merker, Massachusetts General Hospital; Victor Mautner, University Hamburg Eppendorf.

\section{Study Funding}

Supported by a private grant from the Neurofibromatosis Therapeutic Acceleration Program (Francis S. Collins Scholarship in Neurofibromatosis Clinical and Translational Research) at Johns Hopkins University (A.C.) and the Intramural Research Programs of the Center for Cancer Research of the National Cancer Institute and the National Institute of Arthritis and Musculoskeletal and Skin Diseases (D.C.P.). 


\section{Disclosure}

Dr. Cannon, Dr. Pichard, Dr. Wolters, S. Adsit, G. Erickson, A.J. Lessing, Dr. Li, W. Narmore, C. Röhl, Dr. Rosser, and Dr. Widemann report no disclosures. Dr. Blakeley has served as an unpaid consultant for AstraZeneca and Springworks and a paid consultant for AbbVie and Astellas for work unrelated to this topic. Dr. Plotkin is co-founder of and consults for NFlection Therapeutics, Inc. He has served as consultant for AstraZeneca. Go to Neurology.org/N for full disclosures.

\section{Publication History}

Received by Neurology October 9, 2020. Accepted in final form April 29, 2021.

\section{Appendix Authors}

\begin{tabular}{lll}
\hline Name & Location & Contribution \\
\hline $\begin{array}{l}\text { Ashley } \\
\text { Cannon, }\end{array}$ & $\begin{array}{l}\text { University of Alabama } \\
\text { PhD, MS }\end{array}$ & $\begin{array}{l}\text { Design and conceptualization of the } \\
\text { study; major role in the acquisition } \\
\text { of data; analysis and interpretation } \\
\text { of the data; drafting and revising the } \\
\text { manuscript for intellectual content }\end{array}$ \\
\hline
\end{tabular}

\begin{tabular}{|c|c|c|}
\hline $\begin{array}{l}\text { Dominique } \\
\text { C. Pichard, } \\
\text { MD }\end{array}$ & NIH, Bethesda & $\begin{array}{l}\text { Design and conceptualization of the } \\
\text { study; interpretation of the data; } \\
\text { drafting and revising the } \\
\text { manuscript for intellectual content }\end{array}$ \\
\hline
\end{tabular}

\begin{tabular}{|c|c|c|}
\hline $\begin{array}{l}\text { Pamela L. } \\
\text { Wolters, } \\
\text { PhD }\end{array}$ & NIH, Bethesda & $\begin{array}{l}\text { Design of the study; interpretation } \\
\text { of the data; revising the manuscript } \\
\text { for intellectual content }\end{array}$ \\
\hline
\end{tabular}

Sarah Adsit, Children's Tumor Design of the study; interpretation

$\begin{array}{lll}\text { Sarah Adsit, } & \text { Children's Tumor } & \text { Design of the study; interpretation } \\ \text { MPAS } & \text { Foundation, New York } & \text { of the data; revising the manuscript }\end{array}$ for intellectual content

\begin{tabular}{lll}
\hline Gregg & Neurofibromatosis & $\begin{array}{l}\text { Design of the study; interpretation } \\
\text { of the data; revising the manuscript } \\
\text { Erickson, BA }\end{array}$ \\
& Network, Wheaton &
\end{tabular}

\begin{tabular}{lll}
\hline $\begin{array}{l}\text { Andrés J. } \\
\text { Lessing, }\end{array}$ & Neurofibromatosis & $\begin{array}{l}\text { Design of the study; interpretation } \\
\text { of the data; revising the manuscript } \\
\text { MBA }\end{array}$ \\
for intellectual content
\end{tabular}
MBA for intellectual content

Peng Li, PhD University of Alabama Major role in the acquisition of data; at Birmingham analysis and interpretation of the data; revising the manuscript for intellectual content

\begin{tabular}{lll}
\hline Whitney & University of Alabama & Analysis and interpretation of the \\
Narmore, BS & at Birmingham & $\begin{array}{l}\text { data; revising the manuscript for } \\
\text { intellectual content }\end{array}$
\end{tabular}

Claas Röhl, NF Kinder, Vienna BA
Design of the study; interpretation of the data; revising the manuscript for intellectual content
Appendix (continued)

\begin{tabular}{lll}
\hline Name & Location & Contribution \\
\hline $\begin{array}{l}\text { Tena Rosser, } \\
\text { MD }\end{array}$ & $\begin{array}{l}\text { University of } \\
\text { Southern California, } \\
\text { Los Angeles }\end{array}$ & $\begin{array}{l}\text { Design of the study; interpretation } \\
\text { of the data; revising the manuscript } \\
\text { for intellectual content }\end{array}$ \\
\hline $\begin{array}{l}\text { Brigitte C. } \\
\text { Widemann, } \\
\text { MD }\end{array}$ & NIH, Bethesda & $\begin{array}{l}\text { Design and conceptualization of the } \\
\text { study; interpretation of the data; } \\
\text { revising the manuscript for } \\
\text { intellectual content }\end{array}$ \\
$\begin{array}{lll}\text { Jaishri O. } \\
\text { Blakeley, } \\
\text { MD }\end{array}$ & $\begin{array}{l}\text { Johns Hopkins School } \\
\text { of Medicine, } \\
\text { Baltimore }\end{array}$ & $\begin{array}{l}\text { Design and conceptualization of the } \\
\text { study; interpretation of the data; } \\
\text { revising the manuscript for } \\
\text { intellectual content }\end{array}$ \\
\hline $\begin{array}{l}\text { Scott R. } \\
\text { Plotkin, MD, } \\
\text { PhD }\end{array}$ & $\begin{array}{l}\text { Massachusetts } \\
\text { Boston }\end{array}$ & $\begin{array}{l}\text { Design and conceptualization of the } \\
\text { study; interpretation of the data; } \\
\text { revising the manuscript for } \\
\text { intellectual content }\end{array}$ \\
\hline
\end{tabular}

\section{References}

1. Huson SM, Harper PS, Compston DA. Von Recklinghausen neurofibromatosis: clinical and population study in south-east Wales. Brain. 1988;111(pt 6):1355-1381.

2. Duong TA, Bastuji-Garin S, Valeyrie-Allanore L, Sbidian E, Ferkal S, Wolkenstein P. Evolving pattern with age of cutaneous signs in neurofibromatosis type 1: a crosssectional study of 728 patients. Dermatology. 2011;222(3):269-273.

3. Cannon A, Chen MJ, Li P, et al. Cutaneous neurofibromas in neurofibromatosis type I: a quantitative natural history study. Orphanet J Rare Dis. 2018;13(1):31.

4. Ferner RE. Neurofibromatosis 1. Eur J Hum Genet. 2007;15(2):131-138.

5. Page PZ, Page GP, Ecosse E, Korf BR, Leplege A, Wolkenstein P. Impact of neurofibromatosis 1 on quality of life: a cross-sectional study of 176 American cases. Am J Med Genet A. 2006;140(18):1893-1898.

6. Rosnau K, Hashmi SS, Northrup H, Slopis J, Noblin S, Ashfaq M. Knowledge and selfesteem of individuals with neurofibromatosis type 1 (NF1). J Genet Couns. 2017 26(3):620-627.

7. Wolkenstein P, Zeller J, Revuz J, Ecosse E, Leplege A. Quality-of-life impairment in neurofibromatosis type 1: a cross-sectional study of 128 cases. Arch Dermatol. 2001; 137(11):1421-1425

8. Brenaut E, Nizery-Guermeur C, Audebert-Bellanger S, et al. Clinical characteristics of pruritus in neurofibromatosis 1. Acta Derm Venereol. 2016;96(3):398-399.

9. Guiraud M, Bouroubi A, Beauchamp R, et al. Cutaneous neurofibromas: patients' medical burden, current management and therapeutic expectations: results from an online European patient community survey. Orphanet J Rare Dis. 2019;14(1):286.

10. Plotkin SR, Blakeley JO, Dombi E, et al. Achieving consensus for clinical trials: the REiNS International Collaboration. Neurology. 2013;81(21 suppl 1):S1-S5.

11. Widemann BC, Blakeley JO, Dombi E, et al. Conclusions and future directions for the REiNS international collaboration. Neurology. 2013;81(21 suppl 1):S41-S44.

12. Harris PA, Taylor R, Thielke R, Payne J, Gonzalez N, Conde JG. Research electronic data capture (REDCap): a metadata-driven methodology and workflow process for providing translational research informatics support. J Biomed Inform. 2009;42(2): 377-381.

13. Seidlin M, Holzman R, Knight P, et al. Characterization and utilization of an in ternational neurofibromatosis web-based, patient-entered registry: an observational study. PLoS One. 2017;12(6):e0178639.

14. Hsieh HF, Shannon SE. Three approaches to qualitative content analysis. Qual Health Res. 2005;15(9):1277-1288.

15. Dombi E, Baldwin A, Marcus LJ, et al. Activity of selumetinib in neurofibromatosis type 1-related plexiform neurofibromas. N Engl J Med. 2016;375(26):2550-2560.

16. Gross AM, Wolters PL, Dombi E, et al. Selumetinib in children with inoperable plexiform neurofibromas. N Engl J Med. 2020;382(15):1430-1442. 


\section{Neurology}

\section{Perspective of Adults With Neurofibromatosis 1 and Cutaneous Neurofibromas: Implications for Clinical Trials}

Ashley Cannon, Dominique C. Pichard, Pamela L. Wolters, et al. Neurology 2021;97;S15-S24 Published Online before print July 6, 2021

DOI 10.1212/WNL.0000000000012425

This information is current as of July 6, 2021

\section{Updated Information \& Services}

References

Citations

Subspecialty Collections

Permissions \& Licensing

Reprints including high resolution figures, can be found at: http://n.neurology.org/content/97/7_Supplement_1/S15.full

This article cites 16 articles, 2 of which you can access for free at: http://n.neurology.org/content/97/7_Supplement_1/S15.full\#ref-list-1

This article has been cited by 1 HighWire-hosted articles: http://n.neurology.org/content/97/7_Supplement_1/S15.full\#\#otherartic les

This article, along with others on similar topics, appears in the following collection(s):

All Clinical trials

http://n.neurology.org/cgi/collection/all_clinical_trials

All Health Services Research

http://n.neurology.org/cgi/collection/all_health_services_research

Neurofibromatosis

http://n.neurology.org/cgi/collection/neurofibromatosis

Outcome research

http://n.neurology.org/cgi/collection/outcome_research Quality of life

http://n.neurology.org/cgi/collection/quality_of_life

Information about reproducing this article in parts (figures,tables) or in its entirety can be found online at:

http://www.neurology.org/about/about_the_journal\#permissions

Information about ordering reprints can be found online:

http://n.neurology.org/subscribers/advertise

Neurology ${ }^{\circledR}$ is the official journal of the American Academy of Neurology. Published continuously since 1951, it is now a weekly with 48 issues per year. Copyright (C 2021 American Academy of Neurology. All rights reserved. Print ISSN: 0028-3878. Online ISSN: 1526-632X.

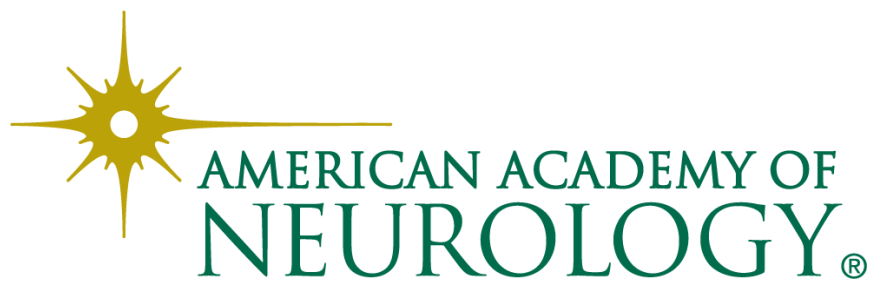

